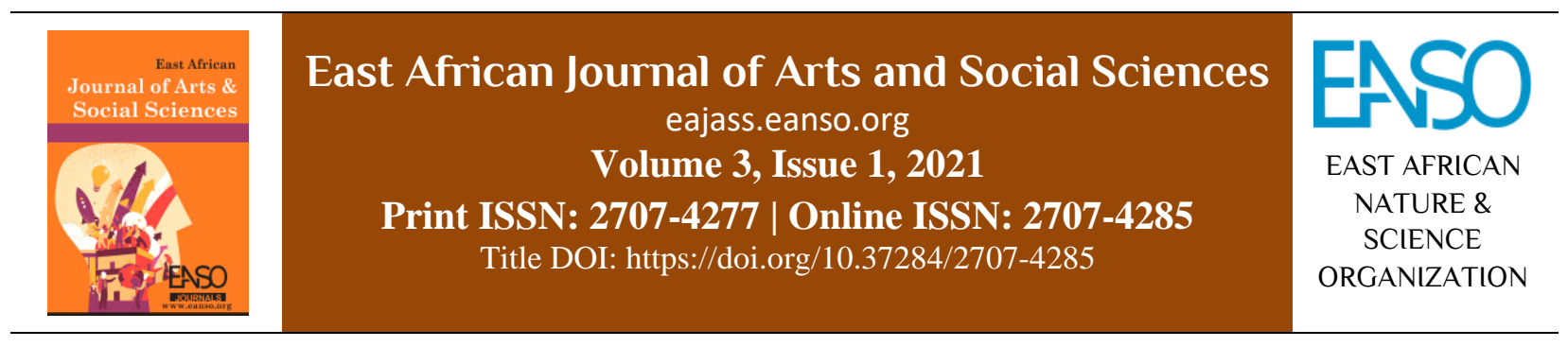

Original Article

\title{
Play with Painting \& Clay: A Re-Booth of Psychoanalysis Healing on a Child Affected By COVID-19
}

\section{Wanyama Ogutu.}

${ }^{1}$ Department of Fine Art \& Design, Kenyatta University. P. O. Box 43844 - 00100, Nairobi, Kemya.

* Correspondence email: wanyamaogutu@outlook.com.

Article DOI: https://doi.org/10.37284/eajass.3.1.290

\section{Date Published: ABSTRACT}

08 March 2021 The world is awakening to the nursing of devastating COVID-19 pandemic effects that resulted in the closure of school among others. Children's welfare,

Keywords: especially playing was obstructed due to COVID-19 pandemic protective and preventive measures set by the World Health Organization (WHO) and other health agencies. Child's development experts asserted that if a child is inhibited A Child, to playing, there are bound to be psychosocial consequences for early childhood development. Educationists together with therapists have applauded Psychoanalysis Healing,

Paintings, Clay, the role play with any art forms goings beyond recreation to an expression of their desires, traumas, and elaboration of their conflicts and emotional healing.

Trauma. This paper has established the psychoanalysis and therapeutic process of a child affected by the COVID-19 pandemic while playing with paintings and clay. The researcher explored desktop descriptive qualitative research design. The psychoanalysis instrumentation was employed to evaluate the literature reviews, theoretical framework on its discussion. The paper has accepted the ravages caused by the COVID-19 pandemic and proposes to education stakeholders to consider playing with paintings and clay to playing groups or pre-schoolers as mitigation measures for a child affected by COVID-19. It has recommended an actual implementation of the study in the post-COVID-19 period once schools open to ascertain its validity.

\section{APA CITATION}

Ogutu, W. (2021) Play with Painting \& Clay: A Re-Booth of Psychoanalysis Healing on a Child Affected By COVID-19. East African Journal of Arts and Social Sciences, 3(1), 35-42. https://doi.org/10.37284/eajass.3.1.290 


\section{CHICAGO CITATION}

Ogutu Wanyama,. 2021. "Play with Painting \& Clay: A Re-Booth of Psychoanalysis Healing on a Child Affected By COVID19”. East African Journal of Arts and Social Sciences 3 (1), 35-42. https://doi.org/10.37284/eajass.3.1.290.

\section{HARVARD CITATION}

Ogutu, W. (2021) "Play with Painting \& Clay: A Re-Booth of Psychoanalysis Healing on a Child Affected By COVID-19", East African Journal of Arts and Social Sciences, 3(1), pp. 35-42. doi: 10.37284/eajass.3.1.290.

\section{IEEE CITATION}

Wanyama O., "Play with Painting \& Clay: A Re-Booth of Psychoanalysis Healing on a Child Affected By COVID-19", EAJASS, vol. 3, no. 1, pp. 35-42, Mar. 2021.

\section{MLA CITATION}

Ogutu Wanyama. "Play with Painting \& Clay: A Re-Booth of Psychoanalysis Healing on a Child Affected By COVID-19". East African Journal of Arts and Social Sciences, Vol. 3, no. 1, Mar. 2021, pp. 35-42, doi:10.37284/eajass.3.1.290.

\section{INTRODUCTION}

Playing with clay and painting is not only a fun activity favoured by the children but also a vessel for healing depression and violent behaviour (Kendall-Tackett, Williams \& Finkelhor, 1993). Botelho (2015) and Schirmacher (2002) alluded that socialisation and communication are major areas of psychoanalysis that play a role in a child's growth and development. In recent years, schools and rehabilitation centres are incorporating playing with clay and painting on child welfare. For instance, the Kenya new ongoing Competency-Based Curriculum (CBC) is addressing the play with clay and painting in psycho-motor and creative as stated in curriculum designs of the Competence-Based Curriculum (Kenya Institute of Curriculum Development, 2017).

The international media news such as $\mathrm{CNN}, \mathrm{BBC}$, CCTV News, Al Jazeera among (March- June 2020) reported that closure of schools and other social places were intended to enforce social distance among their citizens. According to statistics revealed by the EdTech Hub survey (2020), Schleicher (2020), United Nations' COVID-19 Report (2020), and UNICEF Report (2020), show that education sector was most affected by the instigation of social distancing policy as a way of controlling the spread of COVID-19. It noted that the closure of learning institutions exacerbated other challenges such as joblessness and the decline of other businesses. UNICEF Report (2020) and Ngwacho (2020) noted that children's welfares among them play, were affected by the closure of many learning institutions and children's socialisation places. Nandkar (2020) pointed to stress disorder such as worries about the future of children's education, economic stability, selfhealth, and change of routine to have emanated from the COVID-19 curb measures.

Unfortunately, the prolonged reopening of learning institutions and children's social gatherings attributed to the rapid increase of COVID-19 infections were acknowledged as a stressing factor, despite successful online learning according to the United Nations COVID-19 Report (2020) and UNICEF Report (2020). However, online learning did not favour the marginalised children due to poverty background, poor guidance at home, and lack of trained facilitators. This paper has recognised the similar COVID-19 predicament of the past such as World Wars Two, Spanish flu, and HIV AID, among others. It has also acknowledged that exploration of play and art as mitigation measures on such predicament (Gil, 2003). For instance, in Kenya, Wambugu (2015) pointed that aftermath of ethnopolitical violence in 2007, drawings were employed by Non-governmental Organisations in conjunction with the Kenya government as a mitigation tool to children and youths affected by post-election violence. Therefore, the paper has been guided by the following objectives:

i) Re-stated the psychoanalysis therapy to a child affected by COVID-19.

ii) Re-establish the role of play with painting and clay on children affected by COVID-19.

The paper is a response to the call of the United Nations COVID-19 Report (2020) and UNICEF Report (2020) to different stakeholders, including 
scholars to come up with various mitigation measures in the community. Therefore, the paper will be among the tools of mitigations for the traumatised children affected by COVID-19. The findings can be adapted by learning institutions and other children's social gatherings to give different perspectives on new personalities in the postCOVID-19. The study can be actualised into workshops for family, school, and other children's social gatherings such as Sunday schools and other learning areas.

\section{LITERATURE REVIEW}

\section{Play with Clay and Painting}

Botelho (2015) defined play as a free activity of emotion, amusement, recreation, fun, or joke that is mostly involved by children. The study has employed the definition of play on Turner (1992) and Schwartzman (1978) as activities that involve the freedom of mind that without sense, is found outside ordinary life. They pointed out that this kind of play is characterised by non-seriousness that absorbs the player's mind. Play with clay and painting, according to Botelho (2015), are activities that involve the manipulation of different elements anchored in art and craft disciplines. Martin (2009) explained that symbolic play is mostly associated with clay and painting, which involve abstract representational and ambiguous pictures of child expression. A lot of symbolic play in a child is expressed in scribbling (age 1-2) and schematic (age $3-5)$ in the artistic development stage, according to Lark-Horovitz (1967).

Ogutu (2020) pointed out that clay and painting are among art materials/elements used to express feelings or perceptions of the world. Muyanja (2011) defines painting as a method of executing artworks using colour pigments known as paints on distinctive enduring surfaces. Martin (2009) pointed out that paintings contain colourful fluid that is suitable to express on the surface. He noted the process is an exciting and overwhelming process, a time it carries their mind away. Muyanja (2011) looks at clay as a malleable soil material obtained from the swamp that is manipulated by hands. Martin (2009) explained that clay has a smooth tactile feeling that makes it easy to manipulate any abstract representation of three-dimension basic forms. Lark-Horovitz (1967) concluded that play with clay and painting have virtuous elements, which are profound instruments for a child to gain a great understanding of their personality, emotions, and environment. Ruppert (2006), Turner (1992), and Schwartzman (1978) stated that play that involves art and craft are vital learning subjects for a well-rounded personality.

\section{Psychoanalysis Therapy}

Hau and Marianne (2000) viewed psychoanalysis therapy as a clinical theory that is meant to describe a personality treatment. They noted that it is based on the unconscious functionality of a healthy person, psychological illness, mental disorder, and emotional structure. Hau and Marianne (2000) concluded by stating that psychological illness can lead to impaired ability to manage contradictory tendencies of personality or intrapersonal perspective. Malchiodi (2002) explained that psychoanalysis projects itself is in unconscious dreams/daydreams, a slip of the tongue, spontaneous action/decision, and autonomous selfexpression. She outlined other projection evidence on symbolic expression displayed on a child in play. Mclead (2020) noted that personal contradiction occurs in crisis as a result of spontaneous subvention, known as a defence mechanism either through regression, denial, or sublimation as forms of trauma.

Malchiodi (2002) looks at crisis as an object relation or concept of attachment. She noted that object relations are always ingrained in a person, a thing, a situation, and environment or on a mental representative. Hau and Marianne (2000) pointed the crises and calamities are object relations that unconsciously distract personality advancement. They noted that crises and calamities create trauma that distorted perspective, mental stability, emotional sootiness, and attachment capacity.

\section{Trauma}

Talwar (2007) stated that our wall of memories has the attendance of grafting, retaining and, refreshing trauma for days, weeks, months, years, and even decades. He noted that the affected of any crisis ultimately is determined by an individual ability to cope and regulate the distressing situation. Greenwald (2005) explained that one could be adaptive by undergoing all the supportive 
environment system from normal to grief, while others can be overwhelming to the point of seeking emotional and affective relief to object or person. Most of the symptoms of trauma memory known as PTSD can be triggers by the arousal of sounds, images, stories, touch, tests and person, as a reminder of crisis, according to van de Kolk (1994) and Rothschild (2000).

Van de Kolk (1994) pointed out that when there is any crisis, emotions, images, sensations, and muscular are usually imprinted as trauma to a person's mind. He further explained that trauma is replicable if there is no diagnosis of transference, expression, and analytical amplification. Talwar (2007) and Zaidel (2015) report that art activities access the traumatic memory; it involves the left and right hemisphere of the brain. They pointed out that the left hemisphere responsible for language, speech, and analytical thinking works while the right hemisphere is responsible for solving problems and creativities in the form of an image. McNaemee (2004) designed Bilated Art Protocol as a process of manipulating both hands in stimulating memories and experience inside their own brains.

\section{A Child of Age 4-6}

Play with clay and painting works well in a child of age 4-6 term as pre-schooler or playing group is anchored on psycho-motor and creativity development as stated in the design of the Competence-Based Curriculum of Kenya (Kenya Institute of Curriculum Development, 2017). Schirmache (2002) pointed out major characteristics as pre-schematic or symbolic expression noting that this age group communicates and expresses themselves with non-verbal and symbolic play. Berk (1989); Shaffer and Kip (2007) noted that the development of a child age 4-6 is triggered by a social crisis, spontaneous reaction and cognitive development. Ogutu (2020) and Schirmache (2002) pointed out that a child of age 46 has a tendency manipulating and translating ideas, concepts, and experiences with art elements and materials. Schirmache (2002) has alluded that most art activities such as painting and clay, among others, penetrate deeply into a child's mind hence making it easy to display Post Traumatic Stress Disorder (PTSD) symptoms. Lark-Horovitz (1967) pointed out that play that involves art are useful clinical diagnosis and healing therapy to a traumatized child.

\section{Effects of COVID-19 Pandemic}

Ngwach (2020), Nandkar (2020), EdTech Hub Survey (2020), Schleicher (2020), United Nation COVID-19 Report (2020), and UNICEF Report (2020) indicated that the widening of physical contact occasioned by regulation of social gathering in voiding the spread of COVID-19, disrupted over 1.7 billion learners all over the world. They showed that many governments unprecedentedly closed schools without a definite reopening calendar, creating psychological and economic crises among children, parents, education stallholders, and its government. Ngwach (2020) and Nandkar (2020) pointed out that the prolonged reopening of schools led to an upsurge of anti-social behaviour among learners, as reported by many local and international media News. The behaviours were attributed to poor parenting skills at home and negligence of the community. They pointed consequences to hazardous behaviour such as exposure to pornographic materials on the internets, indulged in drugs and alcohol, gender-based violence, sexual exploitation, and defilement of children as reported by CNN, BBC, CCTV News, Al Jazeera, among others (March- Dec 2020).

Ngwach (2020) revealed that schools provide a learning experience of coaching, mentorship, and training that is vital for the development of learners. The closure of schools meant that learner would struggle to survive at home due to economic instability witnessed by the closure of business, loss of jobs by their parents and guardians, and pay cut in some workplaces (EdTech Hub Survey, 2020; Schleicher, 2020; United Nations, 2020; Ngwach, 2020; UNICEF Report, 2020; Nandkar, 2020). Nandkar (2020) noted that the imposed lock-down, made life standstill and people being self-arrested in their own homes. Ngwach (2020) pointed out that so many learner welfares such as playing were obstructed, yet play is a crucial component of intellectual development in humanity according to Gergen (2012). Most learners were indoors bored, sleeping, idling and some loitering in the streets committing petty crimes. EdTech Hub Survey (2020), Schleicher (2020), United Nation COVID19 Report (2020), and UNICEF Report (2020) 
predicted that many children might not come back to school or normality due to psychological and economic issues experienced due to the pandemic.

\section{DISCUSSION}

\section{The Manifestation of PTSD on a Child Affected by COVID-19 Pandemic}

In the course of post-COVID-19, a child is likely to experience the following Post Traumatic Stress Disorder (PTSD) symptoms of COVID-19; flashbacks and nightmares of the incident of COVID-19, avoidance of reminders of COVID-19 images, sound or discussion; hyperarousal, hypervigilance, and emotional dysregulation that come COVID-19 triggers; impairments to memory to those that were directly infected or their close relative, and some will have challenges with interpersonal relationships due to different effects of COVID-19 (Ford and Cloitre 2009). In the postCOVID-19 calamity (Klorer 2005), a child may be unproductive in meaningful activities of schools or social gatherings, and learning institutions. Lieberman et al. (2007) believe that play with painting and clay addresses the visual-spatialcognitive connections, and information processed in brain trauma. The play with clay and painting activities serve to integrate right and left-brain functions; this helps to integrate traumatic experiences of COVID-19 (Bremmer 2002; Solomon \& Siegel, 2003). The process of play, like the splashing of colours on the surfaces, allows a child to express their own images, even sense of the lived experience of the trauma of COVID-19 in ways that are uniquely personal and culturally situated (Cassou, 2001; McNamee 2006; Talwar, 2007).

\section{The Flashing of COVID-19 Ravages through Symbolism}

Play that involves the manipulation of clay is an ideal traumatic memory treatment and the cognitive-affective impairments to vivid COVID19 images, and its sensations on linguistic (van der Kolk 2002, Lieberman et al., 2007). A child affected by COVID-19 may have difficulty using symbols to translate visual and sensory-motor representations into relevant symbols (Taylor, 2010; Miller \& Johnson, 2012). Play with clay may become part of the healing mechanism, where a child creates a variety of symbols associated with the traumatic event. Then a child learns how to change those symbols into more adaptive representations. In this case, the ability to shift symbols has been associated with behavioural change (Taylor, 2010; Miller \& Johnson, 2012). Playing with clay and painting creates faulty interpretations of the traumatic experience and correction narrative, pointing directly to cognitive restructuring.

\section{Recreating COVID-19 Traumatize Scene}

Once schools and children gathering reopens, there will be intolerance and emotional responses will always carry the day due to the affected of COVID19 on healthy psycho-emotion. So, playing with clay and painting may be one way of recreating the scene of one's trauma. It will allow a child to attend to this COVID-19 experience, (van der Kolk 2003). The experience will help to address, reduce and eventually eliminate negative experiences incurred from addressing trauma, such as avoidance and reactivity (Steele, 2003). Splashing and scribbling of colours on the surface, and clay modelling during play is believed to have a natural form of stress hyperarousal and hypervigilance reduction (Stuckey and Nobel 2010). It allows for the desensitisation of anxiety and a better understanding of affective states.

\section{Re-impairing Lost Memories and Concentration}

According to EdTech Hub Survey (2020), Schleicher (2020), UNICEF Report (2020) and United Nation COVID-19 Report (2020), a good number of children are affected by COVID-19 through sexual abuse, domestic violence, and some exposure to pornographic materials. They revealed that a child's learning capacity is affected by the COVID-19 pandemic. A child affected by COVID19 may experience cognitive impairments that impede learning new material, memorisation, concentration, and attention in a learning environment. Once the children resume school or social gatherings, the traumatised COVID-19 child may feel unsafe, blanketed by loss, and burdened by severe traumatic distress. Play with clay and painting may become a way to endorse educational efforts in response to a child affected by COVID19. This may be a therapeutic means through which 
to promote learning in children that have suffered loss and trauma for those orphans.

\section{Rebuilding Self-confidence}

Play is known to have emotional content and intimacy in sharing one's images with another (Botelho, 2015). Using the clay and painting within a context of psychosocial treatment is believed to catalyse relationships and foster a heightened sense of empathy (Peloquin 1996). A child involved in playing with clay and painting builds self-esteem, creates feelings of mastery and competence. Playing with clay and painting also increases socialisation and enhances the overall psychosocial wellbeing of a child (Carey, 2006; Rousseau et al., 2007). A systematic review by Daykin et al. (2008), asserted the benefits of a child playing with arts. They noted that although participants were chosen by risk factors and trauma symptoms, there were significant declines in self-reported behavioural symptoms, improved teacher assessments, and increases in selfconcept. When playing with clay and painting are well utilised with a child affected by COVID-19, it may become an important medium through which to heal the interpersonal negative consequences of COVID-19 (McArdle et al., 2002).

\section{Sharing Experience on COVID-19}

When a child and caregivers are involved in playing with clay and painting, they are not just spending time, but they will have an opportunity to communicating and sharing experiences of the COVID-19 pandemic (Botelho, 2015; Schirmachae, 2002). It enables the child to express what they see and experience inside out, helping a child and caregivers to be aware of their own difficulties as well as become more aware of the emotions of others (van Nijnatten \& van Doorn, 2007). Engaging in play with clay and painting as a family or community is not only a way of processing negative memories associated with the COVID-19 pandemic but a very real and viable way of creating new joyful ones. Sharing COVID-19 stories through play with clay and painting may be accessible, safe, and tolerable to both a child affected by COVID-19 and the caregivers.

\section{CONCLUSION}

Every child is affected by the COVID-19 pandemic either through infection or its psych-economic negative effects or death of close relatives, family, and friends. The COVID-19 pandemic has shaped every child to a new normal because of a child's formative stage. The ravages of the COVID-19 pandemic are displaying in human life taking various dimensions, and for a child age 4-6 through symbolic display and behavioural change. As schools and other children's social gatherings reopen, COVID-19 trauma is going to be underplayed in children, parents, teachers, and the community. Therefore, there is a need to encourage playing with clay and painting to be in every school or child social gathering because of its' healing diagnosis. Play that involves clay and painting accesses the cognitive child brain areas where trauma memories are mediated and translated to symbols and then to language.

The researcher acknowledges other ongoing mitigating disciplines undertaken on religion, music, and sport among others, and it hoped to expand and receive the partnership, collaboration to actualise the study. This will enable the researcher to assert it validly in schools and social gatherings ounces' reopens with a central focus on helping a child who is affected by COVID-19. Therefore, any proposed study on the subject ought to employ a different scientific methodology with a wider scope. The paper recognise that COVID-19 is biological disease that involves psychoanalysis changes over time, so it will require continuous constant assessment in-person development

\section{ACKNOWLEDGEMENT}

My humble appreciation goes to Prof. Mugendi M'Rithaa, an Industrial designer, educator, and researcher at Machakos University, Kenya - for acknowledging the significance of the paper once schools and other children's social gatherings reopen. I am also grateful to Dr. George Vikiru, a lecturer and researcher in the Department of Fine Art and Design at Kenyatta University for recognising the role of Fine Art and Design as a mitigation measure to a child that has been affected by the COVID-19 pandemic. 


\section{REFERENCES}

Berk, R. J. (1989). "Differential aspects of psychoanalysis of the aged": Discussion. Psychoanalysis \& Psychotherapy, 7(1), 44-48.

Botelho, F. (2015). Playing Children: Realities Created through the work of play. Department of Anthropology, Copenhagen University.

Bremmer, C. (2002). Does stress damage the brain? New York: Norton Professional Books.

Carey, L. (2006). Expressive and creative arts methods for trauma survivors. London: Jessica Kingsley Publishers.

Cassou, M. (2001). Point Zero: Creativity without limits. New York: Jeremy P. Tarcher/Putnam.

Daykin, N., Orme, J., Evans, D., Salmon, D., McEachran, M.,\&Brain, S. (2008). The impact of participation in performing arts on adolescent health and behaviour a systematic review of the literature. Journal of Health Psychology, 13(2), 251-264.

EdTech Hub. (2020). The Effect of Covid-19 on Education in Africa and its Implications for the Use of Technology. A Survey of the Experience and Opinions of Educators and Technology Specialists. EdTech Hub

Ford, J., \& Cloitre, M. (2009). Best practices in psychotherapy for children and adolescents. In C. Courtois \& J. Ford (Eds.), Treating complex traumatic stress disorder: An evidence-based guide. New York: Guilford.

Gergen, K. J. (2012). Toward transformation in social knowledge. Springer Science \& Business

Gil, E. (2003). Chapter 12: Art and play therapy with sexually abused children. In Malchiodi, C. A. (Eds), Handbook of Art Therapy (pp. 152-166). New York: Guilford Press.

Greenwald, R. (2014). Child trauma handbook: A guide for helping trauma-exposed children and adolescents. Routledge.

Hau, S. \& Marianne, B. (Eds). (2000). Psychoanalytic Therapy. German Society for Psychoanalysis.
Kendall-Tackett, K. A., Williams, L. M., \& Finkelhor, D. (1993). Impact of sexual abuse on children: a review and synthesis of recent empirical studies. Psychological Bulletin, 113(1), 164-180.

Kenya Institute of Curriculum Development (2017). Education System - 2-6-3-3-3. Basic Education Framework Curriculum; Competence Base Curriculum. Nairobi: Kenya Institute of Curriculum Development.

Klorer, P. G. (2005). Expressive therapy with severely maltreated children: Neuroscience contributions. Art therapy, 22(4), 213-220.

Lark-Horovitz, B. (1967). Understanding children's art for better teaching. C. E. Merrill Books

Lieberman, M. D., Eisenberger, N. I., Crockett, M. J., Tom, S. M., Pfeifer, J. H., \& Way, B. M. (2007). Affect labeling disrupts amygdala activity in response to affective stimuli. Psychological Science, 18(5), 421-428.

Malchiodi, C. A. (2002). Psychoanalytic, Analytic, and Object Relations Approaches. Boston: Shambhala

Martin, N. (2009). Art as an Early Intervention Tool for Children with Autism. London: Jessica Kingsley

McArdle, P., Moseley, D., Quibell, T., Johnson, R., Allen, A., Hammal, D., \& LeCouteur, A. (2002). School-based indicated prevention: a randomised trial of group therapy. Journal of Child Psychology and Psychiatry, 43(6), 705-712.

Mclead, S. (2020). Defense Mechanisms. Retrieved on October 2020 from Simply psychology, https://www.simplypsychology.org/defensemechanisms.html.

McNamee, C. M. (2004). Using both sides of the brain: Experiences that integrate art and talk therapy through scribble drawings. Art Therapy, 21(3), 136-142.

McNamee, C. M. (2006). Experiences with bilateral art: A retrospective study. Art Therapy, 23(1), 713. 
Miller, R. J., \& Johnson, D. R. (2012). The capacity for symbolization in posttraumatic stress disorder. Psychological Trauma: Theory, Research, Practice, and Policy, 4(1), 112.

Muyanja, M. (2011). Art and Design: A comprehensive guide for creative artists.

Nandkar, R. S. (2020). To Study the Effect of Lockdown on Physical, Mental and Emotional Health of Common People. International Journal of Innovative Science and Research Technology (5)6, 777-785.

Ngwacho, A. G. (2020). COVID-19 Pandemic impact on Kenyan education sector: learner challenges and mitigations. Journal of Research Innovation and Implications in Education, 4(2), 128-139.

O'Brien, F. (2004). The making of mess in art therapy: attachment, trauma and the brain. International Journal of Art Therapy, 9(1), 2-13.

Ogutu, W. (2020). The Dynamics of Art and Craft Curriculum in Enhancing Child Growth and Development. East African Journal of Education Studies, 2(1), 18-24.

Peloquin, S. M. (1996). Art: An occupation with promise for developing empathy. American Journal of Occupational Therapy, 50(8), 655-661.

Rothschild, B. (2000). The body remembers. New York: W.W. Norton \& Company.

Rousseau, C., Benoit, M., Gauthier, M., Lacroix, L., Alain, N., Rojas, M. V., Moran, A., \& Bourassa, D. (2007). Classroom drama therapy program for immigrant and refugee adolescents: a pilot study. Clinical Child Psychology and Psychiatry, 12(3), 451-465.

Ruppert, N. (2002). Critical Evidence: How the Arts Benefit Student Achievement. Washington, DC: AEP.

Schirmacher, R. (2002). Art and creative development for young children (4th Edition). Albany, NY: Delmar Thomson Learning

Schleicher, A. (2020). The impact of COVID-19 on education insights from education at a glance 2020. Paris, France: OECD
Schwartzman, H. (1978). Transformations: The Anthropology of Children's Play. New York: Plenum Press.

Shaffer, D. R. \& Kip, K., (2007) Development of Psychological Childhood and Adolescence. John Wiley \& Sons.

Solomon, M. F., \& Siegel, D. (2003). Healing trauma attachment, mind, body, and brain. New York: W.W. Norton.

Steele, W. (2003). Helping traumatised children. In S. Straussner \& N. Phillips (Eds.), Understanding Mass Violence. New York: Allyn and Bacon.

Stuckey, H. L., \& Nobel, J. (2010). The connection between art, healing, and public health: A review of current literature. American journal of public health, 100(2), 254-263.

Talwar, S. (2007). Accessing traumatic memory through art making: An art therapy trauma protocol (ATTP). The Arts in Psychotherapy, 34(1), 22-35.

Turner, V. (1992). The Anthropology of Performance. New York: PAJ Publications

UNICEF. (2020). COVID-19: Are children able to continue learning during school closures?A global analysis of the potential reach of remote learning policies. New York, NY: UNICEF Data and Analytics Section

United Nations. (2020). Policy brief: Education During Covid-19 and Beyond. United Nations

Van der Kolk, B. A. (1994). The body keeps the score: Memory and the evolving psychobiology of posttraumatic stress. Harvard review of psychiatry, 1(5), 253-265.

Van der Kolk, B. A. (2002). Assessment and treatment of complex PTSD. Treating trauma survivors with PTSD, 127-156.

Van der Kolk, B.A. (2003). Frontiers in trauma treatment. Presented at the R. Cassidy Seminars, St. Louis, MO, 2004.

Van Nijnatten, C.,\& van Doorn, F. (2007). Creating communication: self-examination as a therapeutic 
East African Journal of Arts and Social Sciences, Volume 3, Issue 1, 2021

Article DOI: https://doi.org/10.37284/eajass.3.1.290

method for children. Journal of Social Work Practice, 21(3), 337-346.

Waller, D. (2006). Art therapy for children: how it leads to change. Clinical Child Psychology and Psychiatry, 11(2), 271-282.

Wambugu, J. (2015). Effects of Drawing Approach and Class Setting on Symbolism of Children's Drawings on Conflict Experiences: A Study of Primary School Pupils in Nairobi County, Kenya. Unpublished PhD. Thesis, Kenyatta University

Zaidel, D. W. (2015). Neuropsychology of art: Neurological, cognitive, and evolutionary perspectives, 2nd edition. Oxon, OX: Routledge. 